\title{
The sleep specialist in the post-scientism era 2030
}

Keywords: holistic therapist, sleep studies, fatism, BMI, herbal therapy

\section{Opinion}

Archie unlocked the sliding glass door to his surgery as always with his eyes shut. His conscience savaged him every time he read the post-scientism adverts on the wall.

Where he had once displayed his hard-won fellowship, it read 'holistic therapist.' Where it had once displayed his skills in aviation medicine and sleep studies, it now read 'bulkbilling natural medicine.'

Refunds for sleep studies had been abolished. The concept had been deemed offensive to a minority. A group no longer in the minority, as the median BMI had just reached 35. The sale of his now virtually valueless sleep laboratory had covered one month's rent. In the unpublishable vernacular, it had been 'fatism'.

His 'professional' colleagues displayed skills in Bowen Massage, Chiropractic, Herbal therapy, Iridology, Crystal therapy and Tarot card readings. Rebates under the 'New Medicare' were available for all these important treatment modalities. The business man owning his practice had recently doubled rents to support his new Ferrari and holiday mansion in Bali. He owned all the other rental offices in town. Archie could not afford business costs alone now.

His first patient, Rockyanne, waltzed in as much as her advanced pregnancy would allow, flopped in the chair, and put her feet on his desk, 'owyergoinarchmemate' she greeted him.

Rocky had a sad story. Her use of the natural rhythm method of contraception had failed. Unfortunately, the contraceptive pill was no longer available on the PBS since Twitter had revealed it to be the major cause of the chronic fatigue syndrome. She was not particularly concerned as welfare payments for single mothers had doubled, while payments for married women had been ceased.

Rocky's mother had died last month with lung cancer. A life-long smoker of forty a day, she had succumbed to the disease at the age of only fifty-two. Her natural therapy of beetroot, watercress and turmeric, as advised by the herbalist had failed to cure the disease. Her last act was to commence legal proceedings against Archie as her respiratory physician and the thoracic surgeon. Supported by her family, she was suing them for not explaining the gravity of her illness adequately.

Rocky's sister, December-rose, had died last year with cervical cancer, one of five in Archie's practice in six months. Archie could remember a decade ago when not one patient in his practice had cervical cancer over a ten-year period. That was before a documentary about sacrificial lambs and a Facebook campaign outed the HPV
Volume 2 Issue I - 2018

\author{
Peter John Ornsby Stride \\ Consultant Physician, University of Queensland, Australia
}

Correspondence: Peter John Ornsby Stride, Consultant Physician, MBBS (Lond), MRCP (UK), FRACP, FRCPEdin, FRCP, DMed (Res)UQ, Senior Lecturer, University of Queensland, School of Medicine, 23 Aland St, Wavell Heights, Brisbane, Queensland 4012,Australia, Provider Number: 02642I6K, Te +04I 7039 I I I, 073256 7980, Email pjostride@gmail.com

Received: February 14, 2018 | Published: February 22, 2018

vaccine as the sole cause of fibromyalgia, and the unfortunate cause of fifteen fatal car crashes, plus six suicides in the vulnerable two-year window after the vaccine.

Rocky had decided that neither she nor the baby would have the pertussis vaccine. Natural immunity was much better in her opinion. She planned a pertussis party for the baby soon after the birth if she could find someone with the disease. That would give the child natural immunity for life. Archie reflected she would almost certainly find someone with whooping cough in the area, since the incidence had multiplied ten-fold with the withdrawal of government sponsored vaccination campaigns. Archie's importation of Pertussis vaccines had resulted in him facing the medifraud squad for a severe reprimand. They threatened to terminate his licence.

What hurt Archie most was that his parents had named him after his great-grandfather, a founder of the greatest evidence-based collaboration? Every day his conscience told him that the grand old man would be disgusted at the capitulation of his great-grandson to the 'new-think' brigade of the post-knowledge era in control in the national capital.

Archie looked around to ensure he was not being observed. He went to the safe where his prohibited substances were secured and removed his secret copy of 1984 in the hope that the ending may have changed since he last read it.

\section{Acknowledgements}

None.

\section{Conflicts of Interest}

None declared. 